Revista Iberoamericana, Vol. LXXXII, Núm. 254, Enero-Marzo 2016, 137-155

\title{
SUBALTERNIDAD Y NACIÓN EN BOLIVIA DE ADRIÁN CAETANO
}

\author{
POR \\ MoIRa Álvarez \\ Temple University
}

\begin{abstract}
La ciudad del siglo XXI tiene sus extranjeros desconfiables, como los tuvo la ciudad de comienzos del siglo XX. Ya no son los tanos, gallegos, rusos (por rusos blancos y por judíos), moishes, turcos (porárabes), sino los peruanos, los bolitas, los paraguas, los chinos (indiferenciados entre chinos, coreanos, taiwaneses)
\end{abstract}

Beatriz Sarlo, La ciudad vista

En el siglo XIX, a partir de su independencia y los esfuerzos por establecer el Estado moderno, Argentina, a través de sus letrados, se ha imaginado como nación a partir de la presencia extranjera. Domingo Faustino Sarmiento y Rafael Alberdi basaron parte de sus elocuentes argumentos para defender la "civilización" y atacar la "barbarie" en la idea de que se necesitaba una inmigración europea y culta que poblase el territorio y trajese consigo los adelantos asociados con el progreso. "Civilizar es poblar" es el lema que se repite una y otra vezy "poblar es recibir inmigrantes" es el que le seguiría razonablemente de sus propuestas. Como bien apunta Beatriz Sarlo, a consecuencia de esto (y por supuesto también de factores políticos y sociales a nivel mundial), siempre hubo extranjeros en Argentina, especialmente en la ciudad de Buenos Aires, que funcionó durante mucho tiempo como único puerto. Siguiendo algunas de las líneas trazadas por Ricardo Rojas en 1909, Sarlo comenta que, paradójicamente, junto con la gran inmigración creció la idea de salvar a la nación del "caos originario" adonde la condujeron los inmigrantes: creció un miedo a la ciudad contaminada por extranjeros que "hizo despreciar, en los años del primer peronismo, a los cabecitas de las migraciones internas, que desde los años treinta reemplazaron como objeto de preocupación a los inmigrantes europeos de 'mal' origen; finalmente, otros cabecitas de los países limítrofes ocuparon ese lugar" (Sarlo, Ciudad 102). Surgen así los inmigrantes "desconfiables" del epígrafe: peruanos, bolitas, paraguas, extranjeros que Buenos Aires necesita para poder definir su identidad pero a los que recibe con la actitud recurrente de la discriminación -"como si cualquier 
identidad sólo pudiera establecerse sobre un sistema de diferencias ordenadas por los ejes de lo propio y lo ajeno" (Sarlo, Ciudad 102)-.

Bolivia, película de Adrián Caetano, al contar la experiencia de un inmigrante boliviano en Buenos Aires, abre la posibilidad de poner de manifiesto el tema de la discriminación, de lo propio y lo ajeno, del ciudadano y del extranjero, y también, a partir de ahí, de reflexionar acerca de cómo se piensa la nación argentina dada la presencia "perturbadora" del inmigrante de los países limítrofes. La película pone en tensión los estereotipos tanto del inmigrante boliviano como del argentino discriminador (el dueño del bar, los taxistas, el inmigrante de las provincias, etc.) y esto permite, como señala Gonzalo Aguilar, rastrear y descubrir qué hay detrás de ellos: "una obra de arte no sólo debe llevarnos a percibir los personajes estereotipados como tales sino también a mostrarnos la 'instancia estructural' que los produce" (167). En este trabajo, en base al concepto del subalterno, me propongo analizar cómo la película Bolivia problematiza la categoría de subalternidad al presentar y deconstruir la imagen estereotipada del boliviano en Buenos Aires y, consecuentemente, cómo surge y se problematiza a partir de aquí la idea de la nación argentina.

\section{Bolivia y el Nuevo Cine Argentino}

El movimiento que la crítica ha denominado Nuevo Cine Argentino nace a partir de los años 90 y se debe en parte a la proliferación de escuelas de cine y al surgimiento de una nueva generación de directores jóvenes con poca experiencia en la industria cinematográfica. David Oubiña y Gonzalo Aguilar consideran que el punto de partida sería la película Historias breves (1995), la cual por medio de una serie de cortometrajes presentó a los nuevos directores, y que Pizza, birra, faso (1997), de Adrián Caetano y Bruno Estagnaro, sería al film inaugural (film que obtuvo el Premio Especial del Jurado en el Festival Internacional de Mar del Plata). La característica que estas nuevas películas reúnen es que "frente a un cine ineficaz y adocenado, los nuevos films aportaban historias creíbles, narraciones rigurosas, personajes diferentes, diálogos sin impostación y una puesta en escena creativa" (Oubiña 28-29). A pesar de que la producción por supuesto no es homogénea, las consideradas películas del Nuevo Cine Argentino comparten la preocupación por mostrar qué ha quedado después de la dictadura militar (1976-1983), del período de crisis económica de los años 80, de la nefasta década de los 90 (época en que el gobierno neoliberal privatizó la mayoría de las empresas y dolarizó la economía, entre otras cosas) y, finalmente, los films más actuales comparten la preocupación por la crisis económico-política de 2001. Beatriz Urraca considera que las películas argentinas de la década del 90 en adelante responden a un cambio de condiciones de la realidad argentina (un nuevo cine para una nueva Argentina) y al analizar la producción de Pablo Trapero y Adrian Caetano afirma que "these directors are creating a unique

Revista Iberoamericana, Vol. LXXXII, Núm. 254, Enero-Marzo 2016, 137-155 ISSN 0034-9631 (Impreso)

ISSN 2154-4794 (Electrónico) 
audiovisual language that responds to Argentina's need to look at itself and redefine its twenty-first century identity with tools other than the traditional neohistorical and social protest themes that characterized much of the literary and filmic production of the preceding decades" (128).

Adrián Caetano es considerado por muchos críticos uno de los más consagrados directores del Nuevo Cine Argentino que ha logrado construir una obra a través de sus películas y que "sus films constituyen un corpus coherente que, incluso, traspasa los límites cinematográficos para desbordar sobre la televisión” (Oubiña 29). Sus películas han ganado premios en festivales internacionales y un gran respeto entre los críticos. Bolivia (2001) es su segunda película, filmada en $16 \mathrm{~mm}$ y en blanco y negro. En términos de producción, Bolivia se ajusta a las condiciones económicas precarias de gran parte de las películas del Nuevo Cine Argentino: "se sale a rodar con la cámara sin que el objetivo final esté mínimamente garantizado [...] muchas películas se filmaron con lo mínimo indispensable, durante los fines de semana y como sucedáneo de una reunión de amigos" (Aguilar 15). La filmación de Bolivia llevó tres años, los actores y técnicos trabajaron esporádicamente los fines de semana sin recibir ningún sueldo y los lugares en donde se filmó no significaron ningún costo de producción. Joanna Page considera que Bolivia es un caso paradigmático de películas que han nacido de la tensión entre condicionamientos económicos y estéticos, lo que ha dado por resultado "an uncompromising study of a comunity in crisis, riven by a catalogue of prejudices: homophobia, misogyny, xenophobia, and racism" (126). Por otro lado, en el Nuevo Cine Argentino, en oposición al cine anterior a él, no hay una acción pedagógica ni los personajes juzgan la historia desde afuera como sí sucedía con, por ejemplo, $L a$ historia oficial (1985), Tiempo de revancha (1981) y La noche de los lápices (1986). Aguilar considera que la intención es no "bajar línea" sino que por medio de finales abiertos, personajes ambiguos, ausencia de tesis y alegorías, rechazo de una demanda de identidad o política, etc. estas películas logran que la historia tenga cierta opacidad y que puedan abrirse a partir de allí un juego de interpretaciones no condicionadas (27).

Debido a las características de su modo de producción, su propuesta estética y este novedoso compromiso con la realidad, ${ }^{1}$ Bolivia ha recibido diferentes interpretaciones críticas. Algunos, quizás debido a la simpleza del argumento -Freddy, un inmigrante boliviano, llega a Buenos Aires, consigue trabajo en un bar concurrido mayormente por taxistas y termina asesinado por uno de ellos luego de una pelea-consideraron que

\footnotetext{
Aguilar considera que al cine argentino de los ochenta se le puede criticar su costumbrismo, es decir "el apego a códigos de representación que son propios de la literatura realista", Otros mundos 35. El rechazo al costumbrismo de los nuevos directores se basó en la conciencia que tuvieron del desfasaje entre narración y puesta en escena y así, la puesta en escena que evoca lo real no significa que se muestra lo real tal cual es. Coincidimos con Aguilar cuando dice que la realidad no es en blanco y negro pero su uso en Bolivia produce un efecto de registro cotidiano y directo. Ver Otros mundos 36.
}

Revista Iberoamericana, Vol. LXXXII, Núm. 254, Enero-Marzo 2016, 137-155 ISSN 0034-9631 (Impreso)

ISSN 2154-4794 (Electrónico) 
la película juega con los estereotipos de manera simple y así "los personajes resultan chatos, la historia previsible, el conflicto carece de densidad y la puesta en escena se complace con la mera ilustración de un problema social" (Oubiña 29). Otros, en cambio, vieron en la película material para pensar las relaciones sociales, la inmigración y la problemática de una Argentina golpeada por la crisis económica (Aguilar, Urraca y Page, entre otros). Me inclino por esta segunda lectura no sólo porque Bolivia es una de las pocas películas que pone de manifiesto el problema del inmigrante en Argentina, ${ }^{2}$ con lo cual constituye un material privilegiado para el estudio de estas temáticas, sino también porque al detenerse en la construcción del espacio y sus personajes se hace evidente que ambos son mucho más que estereotipos sociales cumpliendo un rol predeterminado.

\section{BOLIVIA Y EL ESTEREOTIPO}

El estudio del sociólogo Alberto Zalles Cueto del año 2002 señala que el Estado argentino estimaba en 1994 la presencia de 2.000.000 de residentes bolivianos en Argentina (de los cuales 1.500.000 estaban en Buenos Aires) ${ }^{3}$ y 700.000 bolivianos indocumentados. Según el autor, la migración de bolivianos es un proceso que se da por ciclos a través de varias generaciones y se caracteriza por no romper definitivamente con su país de origen, tener retornos temporales, un sentimiento de pertenencia a Bolivia muy fuerte y una cierta "endogamia" que cohesiona el grupo de inmigrantes (92). El déficit crónico de mano de obra argentina en ciertas actividades como el trabajo agrícola, la construcción, el servicio doméstico y lo textil fue solucionado por inmigrantes de países limítrofes y esta demanda laboral hizo que desde 1949 el Estado haya dado repetidas amnistías migratorias. Es justamente en los años 90 que se crearon proyectos de regularización e integración, a partir de los cuales surge aquello que Zalles Cueto denomina la 'paradoja argentina', ya que si bien este es un país que se pensó como nación a partir de la posibilidad de poblar territorio por medio de la inmigración y desplegó normas jurídicas de fomento de inmigración limítrofe, por otro lado el Estado y la sociedad manifestaron y manifiestan rechazo y discriminación hacia los inmigrantes.

2 José Fuster Retali traza un panorama de la filmografía argentina desde 1930 a finales de la década del 70 y encuentra que pueden rescatarse tres filmes con este tema: Inmigrantes (1948), Esperanza (1949) y Los gauchos judios (1975). Dentro del Nuevo Cine Argentino, Aguilar menciona que no son muchas las películas con esta temática, y encuentra que únicamente Vladimir en Buenos Aires (2002) y Habitación disponible (2007), ambas del director Diego Gachassin, retoman las historias de inmigrantes.

3 En el interesante recorrido que Beatriz Sarlo propone en su libro La ciudad vista, hay un capítulo dedicado a "Extraños en la ciudad" en el cual luego de referirse extensivamente a la inmigración coreana y sus zonas de asentamiento, Sarlo comenta el "Mural de Castañares", que funciona como bisagra entre el barrio coreano y el barrio que concentra la mayor población boliviana en Argentina: "Barrio Charrúa es ochenta por ciento boliviano. Fue una villa, y hoy sus manzanas tienen el trazado de la villa, pero las casas son de material y los pasillos están ordenados y limpios", 126.

Revista Iberoamericana, Vol. LXXXII, Núm. 254, Enero-Marzo 2016, 137-155 ISSN 0034-9631 (Impreso)

ISSN 2154-4794 (Electrónico) 
Este sentimiento de rechazo es lo que se repite una y otra vez en las escenas de Bolivia problematizando la idea de Urraca de que "after building itself from policies that actively encourage European immigration since the nineteenth century, Argentines of Italian and Spanish descendent must now confront the fact that their country remains a destination for poor immigrants of indigenous physiognomy from neighboring countries" (135). Surge así la discriminación que se pone de manifiesto a través de la creación del estereotipo del boliviano, uno de los más fuertemente difundidos en la cultura argentina, el cual presenta una serie de prejuicios que, como en toda construcción del estereotipo, son independientes de lo que sucede en la realidad: "como no hay una línea real entre el yo y el Otro, una línea imaginaria debe ser trazada" (Gilman 18). A partir de que se traza esta línea, el recorrido del estereotipo permite que este cobre fuerza y se instale en el sentido común de tal manera que se hace casi imposible reconstruirlo o mostrar lo artificial que es (Aguilar 167).

Ahora bien, como Sander Gilman menciona, lo interesante es notar que el estereotipo funciona en varios niveles. A nivel individual, su representante patológico en la película de Caetano sería el personaje del Oso, uno de los taxistas que frecuenta el bar y que, hundido en deudas que no puede pagar, insulta frecuentemente a Freddy, se pelea con él al final de la película y termina matándolo de dos tiros. Más allá del nivel individual, Gilman propone que "it is evident that stereotypes are not random or personal; nor is there some universal soul, a black box that generates these categories of difference. Every social group has a set vocabulary of images for this externalized Other. These images are the product of history and of a culture that perpetuates them" (Gilman 20). De esta manera, el conjunto de clientes del bar en el que trabaja Freddy, principalmente el Oso, funciona como el grupo social que externaliza el lugar común de la cultura argentina sobre el inmigrante boliviano, al mismo tiempo que, como ya mencionamos, lo necesita para afirmarse a sí mismo: "los estereotipos, entonces, expulsan al otro detrás de una línea que puede estar trazada por diferentes juicios ('los bolivianos son ladrones, no se bañan'), que tienden también a preservar la integración del grupo (también imaginario que los emite)" (Aguilar 166). En Bolivia, entonces, colándose en los diálogos de los propios personajes, el estereotipo promueve la distinción entre la "gente de mi país" y la "gente de afuera" a quienes "uno le abre la puerta" y terminan sacándote el trabajo: el Oso no entiende cómo el cordobés, provinciano argentino emigrado a la Capital, no tiene trabajo en el bar y en cambio Freddy sí. En segundo lugar, también como Aguilar nota, los insultos a la "gente de afuera" aparecen hacia distintas nacionalidades - el Oso insulta a un "uruguayo hijo de puta" que lo "cagó", los paraguayos son unos "negros de mierda", los "bolivianos son todos putos", etc. Pero lo más notable quizás respecto a este tema es que aun cuando Freddy repite una y otra vez que es boliviano, el grupo de argentinos le sigue diciendo "peruano" (en la escena en la que Freddy va a hablar por teléfono a una casa que ofrece llamadas de larga distancia tiene que repetir tres

Revista Iberoamericana, Vol. LXXXII, Núm. 254, Enero-Marzo 2016, 137-155 ISSN 0034-9631 (Impreso)

ISSN 2154-4794 (Electrónico) 
veces que la llamada es a Bolivia y no a Perú). Parecería que el estereotipo boliviano está más ligado al aspecto físico y su estatus social que a la nacionalidad y, en este sentido, aparece asociado al racismo que se hace explícito en varios de los insultos que se le imputan a Freddy: "negro muerto de hambre", "negro de mierda". Además, los estereotipos "arise when self-integration is threatened" (Gilman 18) y no por azar es el Oso -quien se siente amenazado por las deudas que no puede pagar-el que incrementa con los días la violencia hacia Freddy. Cuando el dueño del bar, Enrique, le reclama que le pague lo que le debe y lo amenaza con no fiarle más, la única opción del Oso es marcar y acentuar la línea que lo separaría del Otro, el Otro extranjero que llega sin nada cuando en realidad es él quien no tiene nada. "Cualquier paraguayo te duerme en el boliche y yo vengo a dejar la plata acá", dice el Oso haciendo el esfuerzo por diferenciarse del Otro cuando, como bien afirma Aguilar, todo a su alrededor lo lleva a acercársele.

Como consecuencia de estas observaciones, Aguilar concluye que Freddy "no sólo es boliviano (nació en Bolivia) sino que 'parece' boliviano (el estereotipo del boliviano). Se puede ser argentino y parecer boliviano y parecer boliviano o ser boliviano y no parecerlo. Pues bien, físicamente Freddy es y parece boliviano"(Aguilar 169). Coincido con esta apreciación y agrego que el personaje del Oso, por otro lado, es argentino y lo "parece" (el estereotipo del argentino) y que por lo tanto la elección de un actor boliviano que además físicamente cumple con el estereotipo del boliviano para encarnar a Freddy y de uno argentino que cumple con el suyo para encarnar al Oso es un gesto que de por sí desafía aún más al espectador: cómo deconstruir un estereotipo que está en gran medida basado en la imagen o apariencia física cuando justamente se presenta a nuestros ojos con todas esas características. La propuesta de Bolivia va más allá de lo que sería el simple quiebre de estereotipos por medio de un actor boliviano que no lo parezca o un argentino que parezca boliviano (siempre en términos de estereotipos).

En este sentido, más allá de la elección del actor, coincidimos con Aguilar en que el personaje de Freddy no cumple los requisitos del estereotipo, y esto se puede observar en múltiples aspectos. Por ejemplo, Enrique, el dueño del bar, dice que los bolivianos "se quedan quietitos y después te dan el zarpazo" pero en la película Freddy no sólo no es sumiso ni retraído ("quietito") sino que nunca da el zarpazo (es más, es él quien termina asesinado). Además, Freddy "es seductor, elegante y sabe imponer respeto" (Aguilar 169) a diferencia de los clientes del bar que están siempre desaliñados e irrespetuosos. La lengua de Freddy, por otro lado, es muy correcta en términos normativos (en comparación al grupo del bar cuyo sociolecto es muy marcado), y esto se hace explícito en una escena en que el Oso le pide un choripán de mala manera y Freddy responde: "hay que pedir con educación y respeto". Freddy es solidario con Rosa, comparten las propinas y los almuerzos y finalmente es el único que logra una relación sexual consentida con ella cuando todos los clientes del bar, incluyendo al dueño, la desean y creen que "los bolivianos son todos putos". Page analiza la escena en que luego de una secuencia de

Revista Iberoamericana, Vol. LXXXII, Núm. 254, Enero-Marzo 2016, 137-155 ISSN 0034-9631 (Impreso)

ISSN 2154-4794 (Electrónico) 
trabajo intenso, Freddy para un momento para beber satisfecho un vaso de soda y afirma que en esta escena se intenta darle a Freddy un tratamiento diferente al que se le suele dar al Otro: "it is manifestly honest labor that lends Freddy this dignity, his demeanor contrasting with that of the rather self-pitying band of locals who frecuent the bar, out of work or too depressed to work, and drinking away their few remaining pesos" (Page 61). De esta manera, es evidente que la película va deconstruyendo el estereotipo del boliviano 4 a partir de las acciones y gestos de Freddy y, como nota Aguilar, va creando una escisión entre los insultos y comentarios discriminadores y la acción: en un contexto de crisis y desesperación por el trabajo (el Oso tiene deudas, a Marcelo le quedan sólo 50 pesos en el bolsillo, Héctor está desempleado), Freddy no sólo tiene trabajo sino que en al menos dos escenas lo vemos contando dinero (separando las propinas que comparte con Rosa).

La propuesta de Bolivia, filmada en blanco y negro y con actores desconocidos para el público general (salvo el actor que hace del Cordobés que ya había aparecido en Pizza, birra, faso), es distanciarse del estereotipo justamente apelando a él, es decir, presentando y reafirmando visualmente personajes estereotípicos para a partir de ahí desestabilizarlos a través de acciones y del lenguaje. Creo entonces que Bolivia hace un movimiento doble: en uno presenta y a la vez desestructura el estereotipo del boliviano y en el otro reafirma el estereotipo del argentino homofóbico, sexista, racista y discriminador. ${ }^{5}$

Me interesa en lo que sigue indagar cómo se manifiestan las relaciones de poder y control social que se expresan en todo estereotipo prejuicioso y discriminatorio, siguiendo la idea de varios teóricos, entre ellos Ella Shohat y Robert Stam, para quienes el estereotipo "revela las pautas opresivas que se esconden en el prejuicio y que, a primera vista, podrían parecer fenómenos aleatorios e incipientes" (206). El tema de la opresión y las relaciones de dominio y subalternidad aparecen problematizadas en Bolivia ya que, entre otras cosas, los estereotipos "no son errores de percepción sino una fórmula de control social" (Shohat y Stam 207).

4 Estoy de acuerdo con Aguilar en que si bien se contradice el estereotipo, no por eso se cae en el contrario (ver nota 5), "el del héroe intachable", 169. Freddy se pelea, miente (le miente a la policía), es infiel (cuando él la besa, Rosa le dice qué pensarían tus hijas y él responde "mis hijas están durmiendo ahora") y no se sabe manejar bien por la ciudad.

5 En Bolivia no aparecen estereotipos positivos, por lo tanto no hay un contraste entre "buenos" y "malos" sino más bien la deconstrucción del estereotipo negativo del boliviano en Argentina. Según Shohat y Stam, si nos centramos en personajes "buenos" y "malos" lo que sucede es que "el debate deriva fácilmente hacia el moralismo [...] Este tipo de moralismo antropocéntrico, profundamente arraigado en los modelos maniqueos del Bien y del Mal, trata cuestiones políticas complejas como si fueran cuestiones de ética individual", Multiculturalismo 206; énfasis de los autores. Esto evidentemente no es lo que sucede en la película de Caetano.

Revista Iberoamericana, Vol. LXXXII, Núm. 254, Enero-Marzo 2016, 137-155 ISSN 0034-9631 (Impreso)

ISSN 2154-4794 (Electrónico) 


\section{BOLIVIA Y LA SUBALTERNIDAD}

La categoría del subalterno nació de un grupo de historiadores indios que en 1982 publicó el primer volumen de Subaltern Studies donde se proponía elaborar una contrahistoria que tomara como protagonistas a los grupos dominados en lugar de a las élites. Básandose en la noción de subalternidad de Antonio Gramsci, Ranajit Guha definió la subalternidad en el contexto post-colonial de la India como "una condición de subordinación, entendida en términos de 'clase, casta, género, oficio, o de cualquier otra manera"" (citado en Rodríguez). El proyecto pudo extenderse a Latinoamérica más tarde ya que como el mismo Guha observa "it is not territoriality that relates our Project to theirs in a bond of mutual relevance, but temporality. Our Project belongs to our time. It makes its debut at a time of turbulence marked by the difficulties facing India's new nation-state" (35).

El fundadores de los Estudios Latinoamericanos del Subalterno comenzaron a pensar estas cuestiones en 1993 y en el Congreso de LASA (Latin American Studies Association) se constituyeron como grupo. En su 'Founding Statement' se encuentran dos objetivos primordiales: identificar las distorsiones que la cultura oficial o la élite hizo de los subalternos y descubrir las insurgencias que han sido cubiertas a través de la historia (136). El primer objetivo lógicamente está relacionado con los estereotipos ya que a través de ellos, como vimos, se distorsiona la imagen del subalterno y se van creando las relaciones de dominación. El segundo objetivo está relacionado con que el grupo no considera que el sujeto subalterno sea pasivo y que sólo pueda ser movilizado desde arriba, sino que "it 'acts' to produce social effects that are visible, if not always predictable or understandable, by these paradigms or the state policies and research projects they authorize" (137). Ileana Rodríguez, una de sus fundadoras, retoma lo expuesto en este estatuto y explica que la manera en que pueden llevarse a cabo estos dos objetivos es leer a contrapelo ("against the grain"), es decir, debido a que el lugar del subalterno no se construye desde las narrativas hegemónicas o de poder, entonces es necesario hacer una lectura "en reversa" ya que este método "hace posible el campo de sentido de los patrones canonizados por la cultura o por la historia estatal, y pone al descubierto una nueva sensibilidad" (Rodríguez). Florencia Mallon reconoce una cierta tensión irresoluble dentro de los Estudios subalternos ya que, siguiendo ideas de Gayatri Spivak, apunta que hay ciertas limitaciones en poder recuperar la voz e identidad de los subalternos ya que por un lado los archivos y documentos nunca entregan imágenes claras y, por el otro, en el momento en que se le da voz al subalterno, paradójicamente, éste deja de serlo (142). ${ }^{6}$ Sin embargo, ella también encuentra que una buena alternativa

6 Mabel Moraña critica los Estudios subalternos argumentando que el concepto de subalternidad no solo no es nuevo en el imaginario de Latinoamérica sino que en la elaboración actual no puede leerse "más

Revista Iberoamericana, Vol. LXXXII, Núm. 254, Enero-Marzo 2016, $137-155$ ISSN 0034-9631 (Impreso)

ISSN 2154-4794 (Electrónico) 
para al menos aproximarse al sujeto subalterno es esta lectura a contrapelo, que brinda "trozos incitadores de evidencia acerca de la presencia subversiva de voces subalternas, lecturas nuevas y más sensibles a las jerarquías de género de textos clásicos o visiones de las identidades de oposición elaboradas por intelectuales 'periféricos' o de 'minorías", (Mallon 140).

Con estas breves consideraciones, me propongo leer en la película Bolivia la problematización del sujeto subalterno desde varios puntos de vista. En primer lugar, se puede entender que la película de Caetano es en sí misma una lectura a contrapelo de la inmigración de países latinoamericanos a la Argentina ya que, como mencionamos anteriormente, si en los 80 el cine argentino mostró obsesión por dar respuestas políticas e identitarias cerradas y representar a quienes ejercían un poder institucional -personajes militares, comisarios, empresarios, etc.-, en el Nuevo Cine Argentino “antes que mostrar a los representantes del poder, lo que interesa es exhibir los funcionamientos de la maquinaria social y sus engranajes más imperceptibles" (Aguilar 31, nota 22). En este sentido, Bolivia y las películas del Nuevo Cine Argentino estarían haciendo una lectura en reversa del cine precedente y -por qué no- de las relaciones sociales existentes en la Argentina post-dictadura. Como la crítica ha señalado repetidamente, este cine ha tomado por sus protagonistas a marginales, lúmpenes, personajes que "están fuera de lo social", que "no aportan en esa marginalidad la idea de cambio y de heroicidad [...] sino, simplemente, la condición de su exclusión y de la disponibilidad absoluta" (Aguilar 30). ${ }^{7}$

En segundo lugar, evidentemente Freddy es el principal sujeto subalterno de la película aunque aparecen también el caso de Rosa, la empleada del bar que es discriminada por ser paraguaya y mujer (Enrique le dice a Freddy que se cuide de ella porque "esta

que el relato de las estrategias de la resistencia de los dominados del Sur, la historia de la hegemonía representacional del Norte, en su nueva etapa de rearticulación postcolonial", "Boom del subalterno". Ella usa la expresión "boom del subalterno" para dejar en claro que cree que i) la subalternidad es parte de una agenda exterior vinculada al mercado, ii) que las relaciones de subordinación se transforman en campo de conocimiento y entonces se estaría reproduciendo el espacio de poder y iii) que el lugar desde donde se enuncia es en sí un lugar jerárquico -la academia, centros culturales, etc.-; ver "Boom del subalterno". Si bien en este trabajo no discutimos teóricamente la cuestión de los Estudios subalternos, creo que la crítica de Moraña da una vuelta de tuerca a las discusiones del grupo y propone interesantes argumentos para repensar desde dónde y cómo se puede hacer una teoría del subalterno.

7 Si bien esto ha sido así en la mayoría de las primeras películas, creo que es válido lo que Oubiña se pregunta al final de su artículo: si el mérito del Nuevo Cine Argentino ha sido desprenderse del cine más comercial de los 80 y su valor reside en que cada film debe apostarlo todo a riesgo de perderlo todo:, "el nuevo cine deberá decidir si lo que se ha celebrado como un acontecimiento es un simple recambio generacional o una transformación profunda del campo cinematográfico; si se trataba de demoler las convenciones del viejo cine o sólo se buscaban mejorar condiciones de acceso para participar en ellas", 34. Según él, los filmes independientes avanzaron desde los márgenes para empezar a construir un nuevo centro; entre los directores, Caetano es el más prolífico y exitoso y el que quizás se va acercando más a formas del cine convencional; Oubiño 33.

Revista Iberoamericana, Vol. LXXXII, Núm. 254, Enero-Marzo 2016, 137-155 ISSN 0034-9631 (Impreso)

ISSN 2154-4794 (Electrónico) 
tipa es muy turra") y el caso de Héctor, que es provinciano (cordobés) y de quien se sospecha que es homosexual (Enrique le pide que se mantenga quieto, que no mire a sus empleados y que no diga nada como requisito para poder seguir frecuentando el bar). ${ }^{8}$ Debido a que, como ya se mencionó, el estereotipo pone de manifiesto las distorsiones producidas desde el poder, el intento de deconstruir estos estereotipos permite a Bolivia proponer una lectura "en reversa" que exponga las tensiones sociales entre el grupo dominante y el dominado, los argentinos que frecuentan el bar y el inmigrante boliviano respectivamente.

Estas tensiones aparecen representadas en diferentes aspectos. El más notorio, evidentemente, son los insultos, injurias y constantes lugares comunes que se le imputan a Freddy explícitamente desde principio al fin de la película. Sin embargo, creo que interesan más a los fines mi análisis por un lado, el hecho de que Freddy resulta un sujeto remplazable o intercambiable $y$, por el otro, el hecho de que por momentos se vuelve invisible o inaudible, es decir, cuando su presencia es llevada al límite de la subalternidad. Lo primero se pone de manifiesto al analizar la estructura de la película de Caetano, que es circular ya que empieza y termina con Enrique colgando un cartel en la puerta del bar que dice "se necesita parrillero". El cartel del comienzo es lo que desencadena la narración y explica la presencia de Freddy como nuevo empleado del bar, el cartel del final, idéntico al primero, cierra la narración y pone de manifiesto un mismo estado de cosas: la violenta muerte de Freddy no ha cambiado nada la vida del bar (más que el retorno de la necesidad del dueño de volver a encontrar un parrillero). Se entiende que el asesinato de Freddy a balazos, producido en la puerta del bar-exactamente en el límite entre el adentro y la calle-, la presencia de su cuerpo tirado y la sangre chorreando en la vereda no modifican la rutina del espacio del bar más que en la confección de un nuevo cartel idéntico al primero. La estructura misma de Bolivia permite por lo tanto afirmar que para quien representa el poder dentro de este espacio, el sujeto subalterno es desechable y completamente intercambiable. ${ }^{9}$

Respecto a la invisibilidad de Freddy, encontramos que en la escena en que Enrique y uno de los clientes del bar, acodados a ambos lados de la barra donde también está

\footnotetext{
8 No hemos analizado estos dos casos con más detalle porque la película no desarrolla mucho estos personajes ni sus estereotipos. Los insultos a ellos surgen tangencialmente y si bien colaboran con el clima de discriminación generalizada del bar, cada caso en sí no está muy trabajado. Respecto a Freddy, lo que sí se puede señalar es que mientras Rosa funciona como una aliada (comparte las propinas con él, almuerzan juntos en la mesa, van a bailar y tienen una relación sexual), Héctor funciona como la competencia (él y el Oso no entienden cómo Enrique le dio trabajo a una persona extranjera y no a uno de su país).

$9 \quad$ Urraca nota esto mismo en la escena en que el dueño de la pensión donde vive Rosa se expresa respecto a otro inmigrante: "people are expendable, replaceable, and interchangeable, as demonstrated in Bolivia by the hotel owner's resignation when he learns that yet another immigrant had died without clearing out his room first", 142.
}

Revista Iberoamericana, Vol. LXXXII, Núm. 254, Enero-Marzo 2016, $137-155$ 
Freddy sirviéndoles cerveza, hablan explícitamente sobre él como si este no pudiera entender, o no escuchara o directamente no existiera: "Estos tipos se hacen los boludos para pasarla bien" dice Enrique mirando de costado a Freddy. Surge entonces la paradoja de que por un lado la presencia de Freddy como empleado del bar es tan prominente y desconcertante que genera insultos, discriminación y odio y, por el otro, en esta otra escena, ocurre exactamente lo contrario, se habla de Freddy como si no estuviese allí o como si no importase (o quizás como si ya estuviera muerto, anticipando el final). En términos de potencia ofensiva y discriminadora creo que esta escena impacta más que los múltiples y repetidos insultos ya que pone de manifiesto la voluntad de anulación del Otro, lo que es más agresivo que la injuria desmesurada. Vemos también que además de la anulación visual aparece la auditiva ya que los taxistas que frecuentan el bar parecerían no poder o querer escucharlo: la película muestra repetidas veces a Freddy diciendo que es boliviano y no peruano mientras que los clientes del bar afirman que es peruano (a lo que se suma la escena ya mencionada en que los dueños del locutorio ilegal donde Freddy va a hacer una llamada le preguntan varias veces si la llamada es a Perú cuando él repite explícitamente que es a La Paz, Bolivia) y por lo tanto, dentro de este espacio y a pesar de hablar la misma lengua que el resto, las respuestas de Freddy no se escuchan y sus palabras son tergiversadas. El único momento en que parecería que Freddy habla y lo escuchan es cuando le pide al Oso que se retire del bar, ${ }^{10}$ lo que desencadena primero la pelea física que termina con el Oso lastimado y sangrando por la nariz y más tarde el disparo que termina matando a Freddy. Es por lo tanto cuando la voz del subalterno se oye (y se siente la presencia de su cuerpo) que la violencia contenida durante toda la película llega a su punto cúlmine, se convierte en violencia física y desencadena su muerte. Rodríguez señala que en un grupo que se considera homogéneo "que no discute lo social y que presume identidad y transparencia entre signo y referente" (en la película, el grupo del Oso y sus compañeros del bar), "subalterno es todo lo que mortifica" (Rodríguez 10). De esta manera, el Oso se ve expulsado del lugar que para él es lógicamente sólo suyo y de los suyos -el bar de taxistas argentinos- por un inmigrante boliviano que deja por un instante de ser invisible e inaudible y quien con sus palabras y acciones lo "mortifica", lo humilla y amenaza su propia identidad. "Yo no soy ese bolita que está traspirando ahí", dice un Oso desesperado en uno de sus tantos intentos inconducentes de diferenciarse de Freddy. Si en las primeras escenas el Oso se

${ }^{10}$ Lo interesante de este momento es que si bien Freddy se acerca al Oso para pedirle que se retire, lo hace porque Enrique, el dueño del bar, se lo ha pedido (o más bien ordenado). Así, de alguna manera, la voz del subalterno se escucha cuando en realidad 'es hablado' por el dominador. Creo que este hecho complejiza la cuestión y pone de manifiesto el carácter no heroico de los personajes marginales de este tipo de cine que señalaba Aguilar. Este hecho, sumado al desenlace trágico de Freddy, da cuenta de las resistencias de los grupos dominantes a que la voz del subordinado hable por sí misma y no muera.

Revista Iberoamericana, Vol. LXXXII, Núm. 254, Enero-Marzo 2016, 137-155 ISSN 0034-9631 (Impreso)

ISSN 2154-4794 (Electrónico) 
mostraba dueño de la situación, confiado, seguro e insultaba a Freddy constantemente, ya hacia el final es evidente que la presencia de Freddy ha cambiado su situación.

En el estatuto del grupo de Estudios subalternos se considera al subalterno como un sujeto migrante, es decir, inestable "in its own cultural self-representations and in the changing nature of its social pact with the state(s)" (148). Entonces, si la identidad del sujeto subalterno es variada y situacional, la de aquellos que no lo son en un cierto espacio pueden pasar a serlo en otro. De hecho, en el espacio privilegiado del bar el dueño y los clientes son sujetos dominantes, pero fuera de este espacio, en relación a otros sujetos que invisten cierto poder, este grupo se subalterniza. Como Mallon señala, "ninguna identidad subalterna puede ser pura y transparente; la mayoría de los subalternos son sujetos tanto dominados como dominantes, dependiendo de las circunstancias o ubicación en las que los encontramos" (147-148). Para empezar, el bar en el que trascurre la mayor parte de la película está ubicado en una zona periférica de la ciudad de Buenos Aires, no en términos geográficos (la esquina de Pasco y EE.UU. es una zona céntrica, cerca de la mayor estación de trenes llamada Constitución) sino simbólicos: la estética y la clientela del bar muestra un espacio más del margen que del centro y alejado de los espacios de poder. Además, si bien Bolivia no intenta reflejar específicamente la época en que se desató la crisis económica, política e institucional en Argentina en diciembre de 2001, a través de las circunstancias que viven sus personajes pueden verse rastros de esta: "The Crisis was to accentuate the deep divisions that had always existed between the city and the country and between the 'barrio' and the 'villa' in Argentina, making visible the enormity of the chasm between the nation's richest and its poorest" (Page 111). Los clientes del bar son o taxistas que tienen poco trabajo (Marcelo y Mecado) o están endeudados (elOso), o desocupados (Héctor) o borrachos que no pueden levantarse de la mesa del bar. Al igual que lo que sucede con el Oso, estos últimos personajes también intentan diferenciarse de Freddy, siendo que en realidad se le parecen tanto que lo mismo uno como los otros pasan noches durmiendo en una mesa de café. Hay una escena interesante en que se ve a dos clientes durmiendo sentados en una mesa del bar y que insultan a Freddy cuando éste les pide que se retiren si no van a consumir, diciéndole "negro muerto de hambre, cagón”. Pero como Aguilar nota, “qué describe la fase hecha 'muerto de hambre' si quien la dice debe dormir en los bares porque no tiene donde 'caerse muerto' y quien la recibe se encuentra trabajando?" (170). Describe, básicamente, que este grupo de clientes del bar son individuos que sufren los mismos padecimientos económicos que Freddy (hay una escena en que vemos a Freddy pidiendo un café en otro bar y recostándose a dormir sobre la mesa) pero que se sienten diferentes y superiores a él. Estos personajes, como ya vimos, subalternizan a Freddy en el espacio del bar, pero son subalternizados fuera de él. Aunque son pocos los ejemplos porque justamente en Bolivia el espacio del bar funciona como un mundo casi cerrado, hay referencias al afuera de las que puede deducirse el lugar de sujeto subalterno que estos

Revista Iberoamericana, Vol. LXXXII, Núm. 254, Enero-Marzo 2016, 137-155 ISSN 0034-9631 (Impreso) 
tienen fuera de su espacio: por ejemplo, el Oso tiene un problema legal (justamente con otro extranjero, un uruguayo) y repetidas veces comenta que su abogado no lo atiende ni lo ayuda a ganar el juicio. Y en este sentido, es interesante el papel que juega la película que están pasando en la televisión del bar, ya que esta es una producción estadounidense que tiene algunas escenas filmadas en Buenos Aires. Cuando Marcelo reconoce el lugar y la trama de la película, dice "siempre los malos son latinos, latinoamericanos, negros, hasta haitianos, cualquiera, son de terror". Para Marcelo, quienes son "de terror" son los EE.UU., los que dominan, estereotipan y subalternizan a los latinoamericanos (lo que incluye argentinos y bolivianos por igual). Así, en la proyección de la película y la reacción de los clientes del bar puede observarse aquello que Page señala de que de alguna manera, en el espacio que se abre fuera del bar, el grupo de clientes y Freddy están en la misma posición: "neither migrant nor citizen carry any message of salvation, and both are equally embroiled in a hostile society divide not just along lines of race or provenance but also by class, socioeconomic position, gender, sexuality" (113). Bolivia, por lo tanto, sugiere que la presencia de Freddy desencadena diferencias irreconciliables entre el inmigrante boliviano y el ciudadano argentino a la vez que, de manera menos evidente, pone de manifiesto y afirma que tanto uno como otro son parte de la misma sociedad que les es hostil y en la cual, frente a otros poderes, ambos se encuentran en la misma situación. Estas consideraciones serán el punto de partida del próximo apartado, en el cual me propongo indagar cómo se construye la idea de nación argentina en una película que lleva por título el nombre de su país vecino, Bolivia.

\section{BOLIVIA Y LA NACIÓN ARGENTINA}

La relación entre la categoría del subalterno y la de nación puede establecerse, entre otras cuestiones, a partir de lo que Rodríguez señala como uno de los propósitos de los Estudios Subalternos de reconocer el lugar del Estado moderno como normatizador de la historia, ya que la subalternidad "se discute ahora a través de los significados de los conceptos de ciudadanías, hegemonías, subordinaciones, sociedad civil, espacio público y gobernabilidades" (6). En países latinoamericanos post-coloniales, el Estado es un Estado moderno europeo que ha ido creando relaciones entre élites y subalternos basadas en la dominación, es decir, en la subordinación por la fuerza y no por el consenso o la persuasión (lo que se entiende como hegemonía). En este sentido, en el Estatuto del grupo de Estudios Subalternos, se presenta la nación como un espacio al menos dual y, por sobre todo, como un espacio de contraposición y colisión ("Founding Statement" 143). La nación, como modelo no armonioso, incluye múltiples lenguas, razas, etnias, géneros y clases que conviven en la tensión entre la asimilación y la confrontación.

Por otro lado, Benedict Anderson en su libro de 1983, Imagined Communities. Reflections on the origin and Spread of Nationalism, reconocía que el discurso sobre la

Revista Iberoamericana, Vol. LXXXII, Núm. 254, Enero-Marzo 2016, 137-155 ISSN 0034-9631 (Impreso)

ISSN 2154-4794 (Electrónico) 
nación es muy mediocre pero que como idea o sentimiento la nación es muy poderosa y propone entenderla como una "imagined political community - and imagined as both inherently limited and sovereign" (6). La comunidad es imaginada como limitada ya que aún la más grande y populosa de las naciones tiene sus límites, en el sentido de que sus ciudadanos se imaginan parte de una nación pero no de otra. Y se imagina soberana porque el concepto de nación nace en la época de la revolución y el Iluminismo y por lo tanto de la caída del orden divino (Andreson 7). Arjun Appadurai amplía y extiende la noción de comunidad imaginada de Anderson y propone el concepto de "mundos imaginarios", definidos como "the multiple worlds which are constituted by historically situated imaginations of persons and groups spread around the globe" (2). En una época como la actual, signada por grandes migraciones e importantes avances tecnológicos, el concepto de "mundos imaginados" permite ajustar mejor la descripción a un estado de cosas en donde la idea de la nación no ha dejado de existir (más bien todo lo contrario), sino que debe ser revisada o ampliada. Los mundos imaginarios están construidos a partir de diferentes "paisajes" (landscapes), es decir, Appadurai entiende que para explorar el mundo global de hoy, es necesario considerar cinco dimensiones o tipos de paisajes: el etnopaisaje, el mediapaisaje, el tecnopaisaje, el financipaisaje y el ideopaisaje (mi traducción). El etnopaisaje, en particular, está definido como el paisaje que se constituye con las personas que cambian el mundo en el que vivimos -turistas, inmigrantes, refugiados, exiliados y otros grupos o personas que se desplazan y que afectan el espacio al que llegan (Appadurai 2)- y es relevante, por lo tanto, para aproximarse al concepto de nación argentina que la película Bolivia propone. Al trabajar con la presencia de un extranjero y con el estereotipo del inmigrante boliviano, la película pone de manifiesto no ya dónde están sino cómo se imaginan los límites de la nación. ${ }^{11}$ Todo lo que se pueda decir de cómo aparece la nación argentina en Bolivia tiene que ver con esta dimensión imaginaria y con la idea que no hay que perder de vista de que "communities are to be distinguished, not by their falsity/genuineness, but by the style in which they are imagined" (Anderson 6).

La película comienza con la voz en off de Enrique explicando el funcionamiento del bar mientras va pasando una serie de imágenes que definen el ambiente y sitúan la acción. En orden de aparición, estas son: un reloj de pared, una máquina de café, una parrilla, una foto de Juan Carlos Gardel en la pared, el escudo de un club de fútbol, la formación de un

11 Ana Amado analiza el fenómeno del Nuevo Cine Argentino en relación a los márgenes. Respecto a Adrián Caetano, se centra especialmente en su tercera película, Un oso rojo (2002), y llama la atención sobre la escena en donde se canta el Himno Nacional en una secuencia que alterna la escuela en donde el Oso ha ido a dejar a su hija y el asalto violento en que participa a continuación. Amado cree que el recurso a los símbolos patrios se usan para invertir su significado y que "la experiencia que arriesga Caetano de esta simultaneidad entre rapiña feroz y conmemoración (entre institución y delito) se deja apreciar como una provocadora puesta al día de la noción de 'comunidad imaginada' (Anderson) en su versión local", Otros mundos 90.

Revista Iberoamericana, Vol. LXXXII, Núm. 254, Enero-Marzo 2016, 137-155 ISSN 0034-9631 (Impreso)

ISSN 2154-4794 (Electrónico) 
equipo de fútbol local y de Maradona gritando un gol con la camiseta de Boca Juniors, una foto de la selección argentina festejando un gol, los edictos de habilitación del bar, un póster promocionando Goya (una ciudad en la provincia de Corrientes) y finalmente el cartel que dice "se necesita parrillero/cocinero". ${ }^{12}$ Evidentemente el espacio del bar se construye cuidadosamente, desde el comienzo mismo de la película, con objetos e imágenes que contienen una fuerte carga de historia y de "argentinidad": el fútbol, Gardel, la parrilla. Esta construcción se opone a aquellos espacios denominados "no lugares" que propusiera Marc Augé y que Sarlo retoma para hablar de los shopping centers de la ciudad de Buenos Aires postmoderna. El shopping, entre otras características, es un espacio que es igual en todos lados (Minnesota, Miami Beach, New Port, Santa Fé y Coronel Díaz), que ha sido construido para reemplazar a la ciudad y que, sobre todas las cosas, no tiene historia: "la historia está ausente [...] La historia es usada para roles serviles y se convierte en una decoración banal: preservacionismo fetichista de algunos muros como cáscaras" (Sarlo, Escenas 17). El bar de don Enrique presenta exactamente las características opuestas a las del "no lugar" al estar situado en un barrio donde los clientes siguen practicando la antigua y cotidiana costumbre de pasar horas sentados en la mesa de un bar, al tener una arquitectura vieja llena de marcas del pasado y estar colmado de imágenes clásicas de la cultura argentina. Si como Sarlo propone, el shopping es puro futuro e impersonalidad - "frente a la ciudad real, construida en el tiempo, el shopping ofrece su modelo de ciudad de servicios miniaturizada, que se independiza soberanamente de las tradiciones y su entorno" (Sarlo, Escenas 16)- el bar de Bolivia es puro pasado y argentinidad, y esta construcción de "argentinidad" hace aún más sobresaliente la presencia de Freddy, el extranjero boliviano en su primer día de trabajo. Además, lo argentino, en esta primera secuencia, parecería estar marcado tanto por la unidad -la foto de la selección argentina festejando un gol muestra a los jugadores abrazados y unidos en el sentimiento que generan las selecciones nacionales- como por el límite: el póster que promociona Goya, localidad de la provincia de Corrientes,

12 Intercaladas entre estas imágenes aparecen las de los utensillos que se usan en la cocina: las hornallas, cuchillos, vasos con servilletas, azucareras, etc. Page hace una lectura de esta secuencia de utensillos que es contraria a la que propone Christian Gundermann, quien cree que estos objetos en desuso expresan "a kind of alienation within an era of commodity fetishism", citado en Page 59. Page, por el contrario, cree que la insistencia en estos objetos llama la atención acerca del contexto socioeconómico de la Argentina de la crisis y encuentra que más que objetos "perdidos" y sin relación con la trama de la obra, estos ponen de manifiesto la importancia del trabajo y que "the context in which these objects are defamiliarized is perhaps less signally one of commodity fetishism (as Gundermann would have it) than one of the revalorization of any form of labor in the context of severe and increasing unemployement", 60. Si bien no me detendré en el análisis de estos objetos ya que no entran en relación con el concepto de nación que me interesa estudiar, me inclino por la propuesta de Page ya que creo que no solo al comienzo, sino durante toda la obra hay una insistencia en mostrar en detalle el trabajo como una actividad si no satisfactoria (como sí cree Page que es), por lo menos aliviadora de preocupaciones y situaciones desesperadas.

Revista Iberoamericana, Vol. LXXXII, Núm. 254, Enero-Marzo 2016, 137-155 ISSN 0034-9631 (Impreso)

ISSN 2154-4794 (Electrónico) 
tiene en su costado izquierdo el escudo argentino, detalle que permite entender que las ciudades de provincia pertenecen a la nación argentina (como sucedía con el caso de Héctor, el cordobés, quien representaba la "gente de acá" en contraposición a la "gente de afuera”, de Bolivia, de Perú, de Uruguay). Este póster, con el que queda claro qué se incluye en la nación, presenta un interesante contraste con la secuencia de imágenes de la televisión que se van intercalando en los primeros minutos de la película, en las que el seleccionado boliviano se "enfrenta" con el argentino en un partido de fútbol y, por lo tanto, con estas imágenes queda claro qué no se incluye en la nación.

Podemos decir entonces que es en los primeros minutos de película que se construye el espacio nacional y sus límites y, a la vez, se establece qué símbolos se le asocian (el fútbol, el tango, la parrilla). Las imágenes de los dos edictos de habilitación del bar expedidos por la policía de alguna manera "legalizan" este espacio (que por otro lado emplea trabajadores sin papeles o con papeles en trámite, según lo que le dice Freddy a Enrique al comienzo de la película) y también, al estar intercaladas con las demás, "legalizan" estas otras imágenes, es decir, afirman y le dan legitimidad a los símbolos estereotípicos de la argentinidad.

Por otro lado, respecto a la constitución del espacio, creo que es necesario mencionar que la película insiste en mostrar al bar como un espacio cerrado, no solo en términos de un ambiente y un grupo sofocante para Freddy, sino en términos literales: hay dos escenas en que se ve a Enrique cerrando la puerta y tomándose su tiempo para ponerle rejas, lo que nos lleva a pensar que, si el bar funciona como el espacio nacional argentino con todas las características mencionadas, la insistencia de las rejas pondría de manifiesto tanto la necesidad de forzar como de reforzar sus límites. Por otro lado, las rejas tienen una función protectora, lo que resulta en la imagen paralela a la de la "barrera" que se hace en los partidos de fútbol para evitar que el equipo contrario meta un gol y que aparece en una escena del partido que se repite en el televisor del bar, escena que el relator, cuando la selección argentina mete un gol, curiosamente insiste en repetir: "Qué barrera mal armada la de los bolivianos" (énfasis mío). Las rejas-barrera de los argentinos del bar de Bolivia pretenden estar bien armadas, pero evidentemente la presencia de Freddy no sólo lo desmiente, sino que desencadena, en el grupo de clientes, la amenaza (por qué no darle trabajo a la "gente de acá"), los insultos descalificadores y racistas y la posterior violencia y muerte.

Finalmente, cabe mencionar que en la película de Caetano los clientes del bar son ciudadanos argentinos que continúan pensando o imaginando la nación según el pensamiento eurocéntrico y la fuerte dicotomía "civilización" y "barbarie" que propusiera D. F. Sarmiento ya en 1845 y se propagara a través de los siglos. De hecho, el mito de Buenos Aires como "la París de Latinoamérica" no hace más que reforzar un imaginario que ha concebido la ciudad, desde el siglo XIX, como europea: "La comparación de Buenos Aires con París [...] es una imagen del deseo. Resultó del voluntarismo político

Revista Iberoamericana, Vol. LXXXII, Núm. 254, Enero-Marzo 2016, 137-155 ISSN 0034-9631 (Impreso) 
y cultural de las elites que proyectaron la ciudad moderna desde 1880" (Sarlo, "Buenos Aires" 31). En este imaginario que fusiona Buenos Aires-París y, por lo tanto, ArgentinaEuropa, la presencia de Bolivia genera rechazo y una urgente necesidad de redefinirse por medio de la discriminación y la diferenciación. Respecto a esto, Page propone que el grupo de clientes que se reúnen en el bar convenientemente efectúan un doble olvido, el de haber sido una colonia y el hecho de ser ellos mismos producto de la inmigración: "national lines in Buenos Aires may be policed only by dint of forgetting its historical status of a colonial settlement and, later, as a city of mass immigration" (127). Si bien esta interpretación es factible, creo que este grupo más bien pondría de manifiesto la permanencia de relaciones sociales coloniales en el período post-colonial, cosa que evidentemente sucede pues, como Aníbal Quijano señala, el proceso de colonización implicó justamente la colonización de las perspectivas cognitivas, es decir "los modos de producir u otorgar sentido a los resultados de la experiencia material o intersubjetiva, del imaginario, del universo de relaciones intersubjetivas del mundo, de la cultura en suma" (210). Suponer que el grupo del bar de Bolivia olvida convenientemente su pasado colonial y sus propios orígenes de inmigrante es imaginar que su perspectiva cognitiva ha sido liberada de la colonialidad, cuando en realidad lo que Bolivia propone, según lo que hemos señalado respecto al estereotipo y el rol del subalterno, es que esto no es así, que la idea de nación argentina como "mundo imaginado" todavía se sigue elucubrando, desde ciertos grupos, como lo hicieran los fundadores del Estado moderno a partir de la independencia en el siglo XIX.

Para concluir, me interesa resaltar un aspecto del final de la película. El espacio del bar, que como vimos aparece al principio como el lugar en donde se suceden imágenes de la "argentinidad", está enrejado y los personajes insisten en hablar de "la gente de acá" y la "gente que no es de acá"; inmediatamente los límites de lo nacional empiezan a problematizarse con la llegada de Freddy, un inmigrante que no solo no pertenece a la nación sino que por ser y "parecer" boliviano, es rechazado e insultado; y finalmente, en una de las últimas escenas, vemos la puerta del bar abierta, con el cuerpo de Freddy caído mitad afuera, mitad adentro. Este final, de Freddy y de Bolivia, se desencadena cuando al Oso ya no le alcanza la violencia verbal y desde las sombras dispara su revólver. De alguna manera, lo que resume o sintetiza su problemática, y la del grupo que se reúne en el bar, es la pregunta que él mismo se hace cuando siente amenazada su identidad: “¿vos te pensás que yo soy ese bolita que está traspirando ahí?” (énfasis mío). La cuestión no pasa por la respuesta a esta pregunta, es decir, por decidir si el Oso es o no es como Freddy; tampoco pasa por querer evitar discursivamente el estereotipo negativo, es decir, por no decir o considerar a Freddy un 'bolita'; la cuestión pasa, a mi entender, por cómo vos te pensás, por cómo ese vos te imaginás como argentino es, en última instancia, cómo se imagina y se autoimagina la nación entendida como lo hace Anderson. La película de Caetano, cuyo protagonista es un inmigrante boliviano y cuyo

Revista Iberoamericana, Vol. LXXXII, Núm. 254, Enero-Marzo 2016, 137-155 ISSN 0034-9631 (Impreso)

ISSN 2154-4794 (Electrónico) 
título es "Bolivia", habla en realidad de la construcción que todavía cierto grupo de argentinos hace de sí mismo y del espacio que imagina como su nación.

\section{OBRAS CITADAS}

Aguilar, Gonzalo Moisés. Otros mundos. Ensayos sobre el nuevo cine argentino. Buenos Aires: Santiago Arcos, 2006.

Amado, Ana. “Cine argentino. Cuando todo es margen". Pensamiento de los confines 11 (Sept. 2002): 87-94.

Anderson, Benedict R. O'G. Imagined Communities. Reflections on the Origin and Spread of Nationalism. Londres: Verso, 1983.

Appadurai,Arjun. "DisjunctureandDifferenceintheGlobalCulturalEconomy." Theorizing

Diaspora: A Reader. Jana Evans Braziel y Anita Mannur, eds. Malden: Blackwell, 2003. 25-48.

Bolivia. Adrián Caetano, dir. INCAA, 2001.

Fuster Retali, José. "La ausencia de la historia argentina en el cine nacional". Cuadernos hispanoamericanos 624 (2002): 77-91.

Gilman, Sander L. Difference and Pathology: Stereotypes of Sexuality, Race and Madness. Ithaca: Cornell UP, 1985.

Guha, Ranajit. "Subaltern Studies: Projects for OurTime." The Latin American Subaltern Studies Reader. Ileana Rodriguez, ed. Durham: Duke UP, 2001. 35-46.

Latin American Subaltern Studies Group. "Founding Statement." The Postmodernism Debate in Latin America. John Beverley, Michael Aronna y José Miguel Oviedo, eds. Durham: Duke UP, 1995. 135-146.

Mallon, Florencia. "Promesa y dilema de los Estudios Subalternos: Perspectivas a partir de la historia latinoamericana". Convergencia de Tiempos. Estudios subalternos / contextos latinoamericanos. Estado, cultura, subalternidad. Ileana Rodríguez, ed. Ámsterdam: Rodopi, 2001. 117-154.

Moraña, Mabel. "El boom del subalterno". Teorías sin disciplina (latinoamericanismo, poscolonialidad y globalización en debate). < http://www.ensayistas.org/critica/ teoria/castro/Mabel.htm>. 11 junio 2015.

Oubiña, David. "El espectáculo y sus márgenes. Sobre Adrián Caetano y el nuevo cine argentino". Punto de vista 76 (2003): 28-34.

Page, Joanna. Crisis and Capitalism in Contemporary Argentine Cinema. Durham: Duke UP, 2009.

Quijano, Aníbal. "Colonialidad del poder, eurocentrismo y América Latina”. La colonialidad del saber: eurocentrismo y ciencias sociales. Perspectivas latinoamericanas. Edgardo Lander, comp. Buenos Aires: CLACSO, 2000. 201-246. 
Rodríguez, Ileana. "Hegemonía y dominio: Subalternidad, un significado flotante". Teorías sin disciplina (latinoamericanismo, poscolonialidad y globalización en debate). $<$ http://www.ensayistas.org/critica/teoria/castro/rodriguez.htm>. 11 junio 2015.

Sarlo, Beatriz. La ciudad vista. Mercancías y cultura urbana. Buenos Aires: Siglo Veintiuno, 2009.

Escenas de la vida posmoderna. Intelectuales, arte yvideocultura en la Argentina. Buenos Aires: Seix Barral, 2004.

"Buenos Aires: El exilio de Europa." Escritos sobre literatura argentina. Sylvia Saítta, ed. Buenos Aires: Siglo Veintiuno, 2007. 30-45.

Shohta, Ella y Robert Stam. Multiculturalismo, cine y medios de comunicación (Crítica al pensamiento eurocéntrico). Barcelona: Paidós, 2002.

Urraca, Beatriz. "ANew Cinema for a New Argentina." CIEHL: Cuadernos Internacional de Estudios Humanisticos y Literatura 7 (2007): 128-151.

Zalles Cueto, Alberto. "El enjambramiento cultural de los bolivianos en la Argentina". Nueva sociedad 178 (2002): 89-103. 
